\title{
Television food advertising and the prevalence of childhood overweight and obesity: a multicountry comparison
}

\author{
Janny M Goris ${ }^{1, *}+$, Solveig Petersen ${ }^{2}$, Emmanuel Stamatakis ${ }^{3}$ and J Lennert Veerman ${ }^{4}$ \\ ${ }^{1}$ School of Population Health, MPH Program (partially funded by Queensland Health), The University of \\ Queensland, Herston, QLD, Australia: ${ }^{2}$ Department of Clinical Sciences, Paediatrics, Umeå University, Umeå, \\ Sweden: ${ }^{3}$ Department of Epidemiology and Public Health, National Institute for Health Research, University \\ College London, London, UK: ${ }^{4}$ School of Population Health, The University of Queensland, Herston, QLD, \\ Australia
}

Submitted 7 April 2009: Accepted 4 November 2009: First published online 17 December 2009

\begin{abstract}
Objective: To estimate the contribution of television (TV) food advertising to the prevalence of obesity among 6-11-year-old children in Australia, Great Britain (England and Scotland only), Italy, The Netherlands, Sweden and the United States.

Design: Data from contemporary representative studies on the prevalence of childhood obesity and on TV food advertising exposure in the above countries were entered into a mathematical simulation model. Two different effect estimators were used to calculate the reduction in prevalence of overweight and obesity in the absence of TV food advertising in each country; one based on literature and one based on experts' estimates.

Setting: Six- to eleven-year-old children in six Western countries.

Results: Estimates of the average exposure of children to TV food advertising range from $1.8 \mathrm{~min} / \mathrm{d}$ in The Netherlands to $11.5 \mathrm{~min} / \mathrm{d}$ in the United States. Its contribution to the prevalence of childhood obesity is estimated at 16\%-40\% in the United States, 10\%-28\% in Australia and Italy and 4\%-18\% in Great Britain, Sweden and The Netherlands.

Conclusions: The contribution of TV advertising of foods and drinks to the prevalence of childhood obesity differs distinctly by country and is likely to be significant in some countries.
\end{abstract}

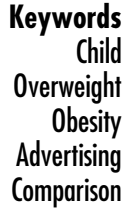

Childhood overweight and obesity is an increasing public health problem ${ }^{(1-3)}$. Often persisting into adulthood, childhood obesity increases the risk of suffering from a range of diseases, including diabetes mellitus and CVD, which can lead to poor quality of life and a shortened lifespan ${ }^{(3-5)}$. Overweight among children is related to many factors at the individual, family and environmental levels.

Cross-sectional and longitudinal studies have shown a positive association between time spent watching television (TV) and an increase in the prevalence of childhood overweight and obesity ${ }^{(6-9)}$; whereas the results of published studies indicate a positive relationship between TV viewing and overweight ${ }^{(10-12)}$, mechanisms driving this are not clear. Two primary mechanisms by which TV viewing contributes to weight gain in children have been suggested: reduced physical activity or increased energy intake or a combination of both. Weak-to-modest inverse associations between TV viewing and physical activity

$\uparrow$ Correspondence address: Queensland Health, Gold Coast Population Health Unit, PO Box 267, Southport, QLD 4215, Australia. have been found ${ }^{(9,13)}$. There is also evidence that at least part of the relationship between TV viewing and overweight in children can be linked to energy intake; that is, TV watching is associated with an increase in consumption of fast food and energy-dense snacks ${ }^{(6,7,12)}$. The present study focuses on the latter mechanism and will explore the potential effect of TV food advertising on childhood obesity.

There is substantial evidence that exposure to TV food advertising significantly influences children's food preferences, choices, purchase requests and food intake, but the strength of the evidence decreases with the length of the putative causal chain from advertising to obesity $^{(8,13-17)}$. The effects appear to be independent of other factors and operate at both brand and category level ${ }^{(18)}$. Studies of TV food promotion show that the commercial marketing of food to children is dominated by unhealthy products, promoting the intake of energy-dense nutrientpoor foods. These products pose a risk of weight gain and obesity in children ${ }^{(3,10,16,19,20)}$. However, research that quantifies the potential relationship between childhood 
overweight and TV food advertising while controlling for TV viewing time, physical activity, parental influences, non-TV-related sedentary time and other contextual factors is scarce. It is also unknown how much of the overweight and obesity in children is attributable to TV food advertising exposure at the population level.

Lobstein and $\mathrm{Dibb}^{(11)}$ found a significant association between the proportion of children with overweight and the number of food advertisements per hour on TV in several countries. The authors estimate that TV food advertising could explain up to half of the variation between the different countries' overweight prevalence figures. However, the Lobstein and Dibb's study made use of data from 1996 on TV advertising to children in thirteen countries, based on an average of only $20 \mathrm{~h}$ of recording on commercial channels ${ }^{(11,21)}$.

The contribution of TV food advertising to childhood obesity is difficult to examine directly. There is little empirical evidence that has been able to quantify the effect of TV food advertising on obesity because of its interrelatedness with sedentary behaviour, consuming snacks while watching and the influence of alternative types of marketing ${ }^{(22)}$. Trials in real-life situations are virtually impossible; it would require the ability to vary exposure to TV food advertising while leaving all other influences constant. We are not aware of any existing study that accomplished this.

However, the existing evidence can be used to construct a logical framework and estimate the impact of TV food advertising using mathematical models. Such models do not remove the need for studies that directly examine the effect of advertising on childhood obesity, but can usefully inform policy decisions by exploring the likely range of the effects of measures to limit children's exposure to food advertising.

The present study builds upon earlier research in which a mathematical simulation model was used to predict the effects of reducing TV food advertising on childhood obesity in the United States, applying CDC2000 definitions for overweight and obesity. The results suggested that one in every three to seven obese children in the United States might not have been obese in the absence of advertising for unhealthy food on $\mathrm{TV}^{(23)}$. However, with its high prevalence of childhood obesity and high amount of TV food advertising, the results from the United States are not directly applicable to other countries. The present study uses the same methods (except that the International Obesity Task Force (IOTF) cut-off values for overweight and obesity ${ }^{(24)}$ are used) and applies these to a range of Western countries. The aim of the present study is therefore to quantify and compare the effect of TV food advertising on the prevalence of overweight and obesity in 6-11-year-old children in Australia, Great Britain (England and Scotland only), Italy, The Netherlands, Sweden and the United States.

\section{Methods}

On the basis of available published literature and other reviews $^{(11,19,21,25-27)}$, three countries were selected with expected higher exposure rates of TV food advertising Australia, United States and Great Britain (England and Scotland only) - and three countries where we expected lower exposure rates - Sweden, The Netherlands and Italy.

\section{Overweight and obesity}

A literature search was carried out using the PubMed database to identify studies in the six different countries that estimate the prevalence of overweight and obesity among 6-11-year-old children. Search terms used were 'child', 'childhood', 'overweight', 'obesity', 'prevalence', 'epidemiology' in combination with country names, and the 'related links' feature in PubMed. Also the IOTF $\operatorname{archive}^{(28)}$ was searched. We included studies if they were published between January 2000 and January 2008, and defined overweight and obesity by BMI $\left(\mathrm{kg} / \mathrm{m}^{2}\right)$ values calculated on the basis of the measured anthropometrics. In a second phase, authors of identified studies were contacted and asked for detailed data on overweight and obesity prevalence rates as well as mean weight and height by age and sex.

In every country, boys and girls were modelled separately in 1-year age categories by fitting the measured prevalence of BMI in the current situation to a log-normal distribution with intercept, using the least squares method. In Fig. 1, the continuous lines illustrate the results for 11-year-old boys. The international reference values of Cole et $a l^{(24)}$ were applied to determine the prevalence of overweight and obesity.

\section{Television food advertising exposure}

Studies on TV food advertising exposure in the six countries were identified through searches of the PubMed database. Search terms used were 'child', 'marketing', 'TV', 'food', 'advertising' in combination with country names, and the 'related links' feature in PubMed. We included studies on TV food advertising if they were published between January 2000 and March 2008. No nationally representative studies that used a standard methodology of data collection were found. Where possible, direct estimates of TV food advertising were used and when not available an average exposure of children to TV food advertising was estimated by combining studies that provided data on the number of TV food and drink-related advertisements per hour during children's viewing time and data on viewing patterns from national media and broadcasting organisations. In case exposure time was not available but studies did report the number of advertisements, we assumed that the average duration of a TV food commercial is $30 \mathrm{~s}$. This was verified with the authors of each study as a reasonable estimate. 

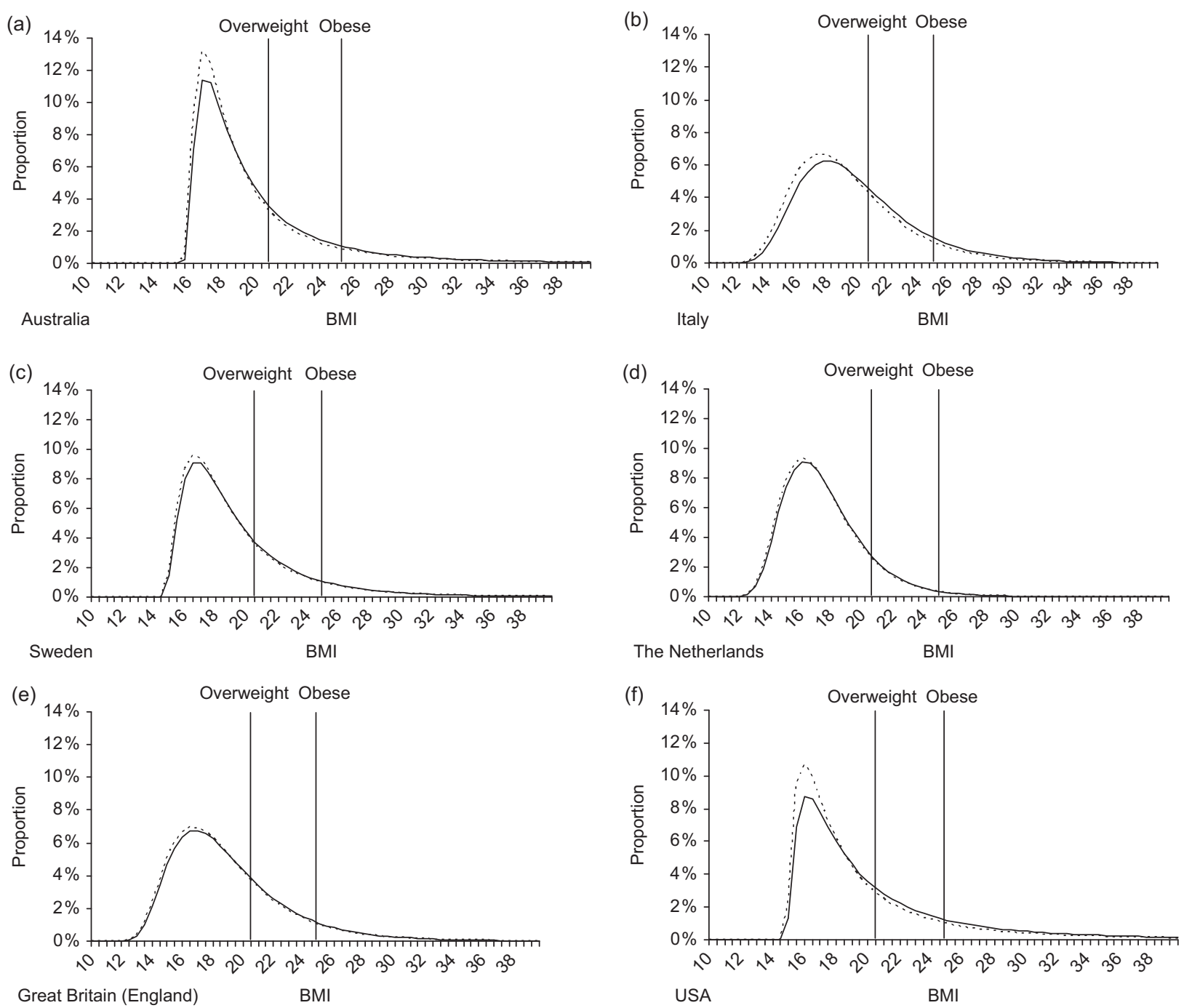

Fig. 1 (a)-(f) Modelled BMI distributions of 11-year-old boys. Illustrations of modelled BMl distributions of 11-year-old boys in all countries are shown. The continuous line denotes the current situation, the dotted line represents the hypothetical distribution in the absence of television food advertising as modelled in the Delphi scenario. The vertical lines indicate the age- and sex-specific cut-off points for overweight and obesity

\section{Analysis}

The effect of TV food advertising on the prevalence of overweight and obesity was estimated using the mathematical simulation model that was developed for the study that focused on the United States mentioned above $^{(23)}$. Two counterfactual scenarios - the 'Bolton' and the 'Delphi' - for overweight and obesity after removing all exposure to TV food advertising are modelled. The prevalence of overweight and obesity in each of these scenarios was compared to the prevalence as calculated above ('current situation' scenario). For each country, the data on BMI distribution and mean weight and height for age by sex, combined with data on TV food advertising exposure, were entered into the model.

The estimation of overweight and obesity prevalence in the counterfactual (no food advertising) scenarios consists of three steps. First, the level of exposure to TV food advertising determines the total daily energy intake. We used two alternative methods for this step: one based directly on the literature ('Bolton scenario'), and the other based on expert opinion ('Delphi scenario'). Bolton ${ }^{(29)}$ estimated that a weekly increase of $25 \mathrm{~min}$ of TV food advertising exposure would increase the energy intake by approximately $1.4 \%$. This value was replaced with $3.5 \%$ in a parallel analysis based on expert opinion obtained in a Delphi study. In the Delphi study, eight (out of thirtythree) researchers who had recently published on the topic, or whom we knew to be knowledgeable, provided their estimate of the effect of TV food advertising exposure on energy consumption ${ }^{(23)}$.

Second, a change in energy intake results in change in the average body weight and (thus) BMI. The model applied Swinburn et al.'s ${ }^{(30)}$ estimate that two populations with a $10 \%$ difference in mean 'EnFlux' (balance energy 
expenditure $=$ energy intake $)$ would have a $4.5 \%(95 \%$ CI $3 \cdot 8 \%, 5 \cdot 1 \%)$ difference in mean weight.

Third, a new log-normal BMI distribution is modelled based on the new (lower) mean BMI. We first derived the mean BMI from the log-normal distributions in the 'current situation' scenario. We then derived the average weight for each age and sex group, and changed this by the percentage that resulted from the previous two steps. Next, assuming the height stable, mean weight was converted back to a new mean BMI value. Assuming the 'sigma' parameter and the intercept of the log-normal distribution stable and changing only the 'mu' variable now allowed deriving the shape of the counterfactual BMI distribution (Figs 1(a) to (f) provide graphical examples). The new BMI distributions had a reduced spread and rightward skew, which means that the section of the population with the highest BMI values are disproportionately affected. The methods have been described in more detail elsewhere ${ }^{(23,31)}$.

In the Bolton scenario, 95\% uncertainty intervals (UI) around the outcomes were calculated by varying the relationship between the number of $\mathrm{kJ}$ consumed and body mass to reflect the $95 \% \mathrm{CI}$ of the source study ${ }^{(30)}$. (UI are comparable to CI, but incorporate uncertainty from various not necessarily statistical - sources.) In the Delphi scenario, simultaneous parametric and non-parametric bootstrapping (5000 iterations) was applied to estimate the combined uncertainty in relationship between the number of $\mathrm{kJ}$ consumed and body mass and the relationship between advertising and BMI as estimated by the Delphi panel ${ }^{(32)}$. Calculations were carried out in MS Excel; bootstrapping with the Ersatz add-in (Ersatz 1·0; EpiGear, Brisbane, Australia).

Reductions in the prevalence of overweight and obesity were calculated by dividing the difference in prevalence rates between the counterfactual Bolton and Delphi scenarios and the observed prevalence rates ('current situation' scenario) on the observed prevalence. This results in estimates of the proportion of currently overweight/obese children that would not have been obese in the absence of TV food advertising.

\section{Results}

\section{Prevalence of childhood overweight and obesity}

Nine cross-sectional studies that examined the prevalence of overweight and obesity in children aged 6-11 years were identified. Two studies were excluded; one because it was a small study including one city only ${ }^{(33)}$ and another because the author did not respond to our request for data ${ }^{(34)}$. Thus, seven studies were available for analysis. Nationally representative data were available only for the United States and Great Britain (England and Scotland only). For the other participating countries, studies based on regional surveys were used under the assumption that these provide the best approximation of the situation in these countries (Table 1).
The lowest prevalence rates of childhood overweight/ obesity were found in The Netherlands and Sweden; Great Britain had a high prevalence rate of overweight/ obesity particularly for boys in Scotland and for girls in England. Italy had a high overweight/obesity prevalence rate for boys and Australia had a high prevalence rate particularly for girls. The highest overweight/obesity prevalence rates for both girls and boys were found in the United States (Table 1).

\section{Exposure to television food advertising}

For the United States, a comprehensive study by Powell et al $^{(22)}$ provided a direct estimate of TV food advertising exposure in 2003-2004 in $\mathrm{min} / \mathrm{d}$. The UK Ofcom report ${ }^{(35)}$ provided data on TV food impacts or TV food advertisements actually seen in Great Britain during 2004. For all other countries, we combined studies that provided data on TV food advertisements and TV-viewing patterns monitored between February 2001 and March 2007. TV food advertising exposure was found to be highest in the United States and lowest in The Netherlands, Sweden and Great Britain, while Italy and Australia took intermediate positions (Table 2). TV viewing and food advertising exposure data used in this study were from before the introduction of advertising restrictions to children in most countries. The average daily TV viewing time in 6-11-year-old children was found to be $90 \mathrm{~min} / \mathrm{d}$ in Sweden, $116 \mathrm{~min}$ in Australia, $120 \mathrm{~min}$ in The Netherlands, $140 \mathrm{~min}$ in Italy, $144 \mathrm{~min}$ in Great Britain and $199 \mathrm{~min} / \mathrm{d}$ in the United States.

\section{Expected changes in overweight and obesity by television food advertising}

The estimated changes in overweight and obesity based on the Delphi study are more than twice as high as those based on the Bolton study (Table 3). The contribution of TV food advertising to the prevalence of childhood obesity ranks highest in the United States, where the Delphi scenario estimated that $40 \%$ (95\% UI 23, 58\%) of obese children would not have been obese in the absence of TV food advertising. In Australian and Italian girls and boys, point estimates were $25 \%-28 \%$ and $11 \%-18 \%$ in Swedish, Dutch, English and Scottish girls and boys. The corresponding point estimates in the Bolton scenario are 16\% for American boys and girls, $10 \%-11 \%$ for Australian and Italian boys and girls and 4\%-7\% for Swedish, Dutch, English and Scottish boys and girls.

\section{Discussion}

Our study attempted to quantify the effect of exposure to TV food and drink advertising on the prevalence of overweight and obesity among 6-11-year-old children by making use of a mathematical simulation model and data from published sources. The results presented suggest a 
Italy All children from three provinces in central Italy; Perugia, Terni and

Sweden

\section{Children selected randomly among} all children attending primary
school in Umeå, Sweden

Netherlands All children routinely surveyed in eleven $(\sim 31 \%)$ community health services in The Netherlands ${ }^{(45)}$

England

Cross-sectional sample children $0-15$ years in the general population living in private households in England. Households were randomised sampling ${ }^{(46)}$

Scotland Cross-sectional sample children $0-15$ years in the general population living in private households in Scotland Households were selected using
multistage randomised sampling

United States National Health and Nutrition Examination Survey (NHANES) based on a stratified multistage cluster selection design linked to the National Health Interview
1993-2001 21544

Socio-economic status of the Directly on data three provinces is population as a whole

2001

913

Umeå reflects the Swedish society in family income structure (Statistic

Sweden, www.scb.se)

2002-2004 $43393 \quad$ Cases weighted for ethnicity and municipality size to match the distribution in the general population

The LMS method was used 95 to calculate the age-

$\mathrm{BMI}$, and the prevalence

was calculated from the

fitted distribution

2002

$4238 \quad$ Not available

2003

2003-2004

98
Directly on data

$$
\begin{array}{ll}
\text { Interviewed: } 79 & \text { Boys } \\
\text { BMI }\left(\mathrm{kg} / \mathrm{m}^{2}\right) & \text { Girls }
\end{array}
$$$$
\text { calculated: } 72
$$

\section{Boys}

$2 \cdot 3 \quad 12 \cdot 2$


Table 2 Selected studies on television food-advertising exposure

\begin{tabular}{|c|c|c|c|c|c|}
\hline Country & Source & $\begin{array}{l}\text { Year of the } \\
\text { data collection }\end{array}$ & $\begin{array}{l}\text { Sampling methods, food advertisements per hour and } \\
\text { TV-viewing time }\end{array}$ & $\begin{array}{l}\text { Geographical area of data } \\
\text { collection }\end{array}$ & $\begin{array}{c}\text { Daily TV food advertising } \\
\text { exposure (assumption 1: } \\
\text { TV food } \\
\text { advertisement }=30 \mathrm{~s} \text { ) }\end{array}$ \\
\hline Australia & $\begin{array}{l}(49) \\
(50)\end{array}$ & $\begin{array}{c}2005 \\
2005 / 2006\end{array}$ & $\begin{array}{l}\text { Recording of } 672 \mathrm{~h} \text { of free-to-air Australian TV during } \\
\text { two weekdays between } 07 \cdot 00 \text { and } 21 \cdot 00 \text { hours } \\
\text { and two weekend days in June } \\
\text { A total of } 3287 \text { food ads were registered in } 645 \mathrm{~h} \rightarrow 5 \cdot 1 \\
\text { food ads/h } \\
\text { TV-viewing time of the } 5-12 \text {-year-old children: } \\
116 \mathrm{~min} / \mathrm{d}\end{array}$ & $\begin{array}{l}\text { Two capital cities and two } \\
\text { regional areas in New } \\
\text { South Wales, Queensland } \\
\text { and Victoria }\end{array}$ & $\begin{array}{l}4.9 \mathrm{~min} / \mathrm{d} \\
(5 \cdot 1 \mathrm{ads} / \mathrm{h} \times 116 \mathrm{TV} \\
\quad \text { viewing in } \mathrm{min} / \mathrm{d} \\
\quad=9.86 \mathrm{ads} / \mathrm{d} \\
\text { Assuming } 1, \mathrm{ad}=30 \mathrm{~s} \\
\quad \text { gives exposure of } \\
\quad 4.9 \mathrm{~min} / \mathrm{d})\end{array}$ \\
\hline Italy & $\begin{array}{l}\text { Personal communication } \\
\text { Chiarieforti Tele Media Net } \\
\text { s.r.l. and Elaborazione } \\
\text { Arianna AGB Nielsen } \\
\text { Media }\end{array}$ & $\begin{array}{c}2001 \\
2001-2002\end{array}$ & $\begin{array}{l}\text { Recording of } 233 \mathrm{~h} \text { of free-to-air Italian TV (RAI, Mediaset, } \\
\text { La } 7 \text { ) with general childrens' programmes on weekdays } \\
\text { and weekend days over three periods in February- } \\
\text { March, April and July } \\
\text { Nineteen ads } / \mathrm{h} \text { were registered of which } 28 \% \text { for } \\
\text { foods and drinks }=5 \cdot 3 / \text { food ads } / \mathrm{h} \\
\text { TV-viewing time of the } 6-12-y e a r-o l d ~ c h i l d r e n: \\
140 \mathrm{~min} / \mathrm{d}\end{array}$ & Italy & $6.2 \mathrm{~min} / \mathrm{d}$ \\
\hline Sweden & $\begin{array}{l}(26) \\
(51)\end{array}$ & $\begin{array}{l}2007 \\
2007\end{array}$ & $\begin{array}{l}\text { Recording of } 72 \mathrm{~h} \text { in March during } 3 \text { days, including } \\
\text { weekday weekend days, from } 06 \cdot 00 \text { to } 09 \cdot 00 \text { and } \\
\text { from } 18 \cdot 00 \text { to } 21 \cdot 00 \text { hours of TV food ads on free-to-air } \\
\text { channel TV4 and Channels Cartoon Network (=Eng), } \\
\text { TV3 and Channel } 5 \text { (=Swedish) with } 3.9 \text { food ads } / \mathrm{h} \\
\text { TV-viewing time of children at } 9-14 \text { years of age: } 90 \mathrm{~min} / \mathrm{d}\end{array}$ & Sweden & $2.9 \mathrm{~min} / \mathrm{d}$ \\
\hline Netherlands & $\begin{array}{l}\text { Personal communication } \\
\text { Stichting Ether Reclame } \\
\text { (2005) and } \text { (52) }^{\text {(200) }}\end{array}$ & 2005 & $\begin{array}{l}\text { Recording whole month of October of all free-to-air } \\
\text { channels; } 1 \cdot 8 \text { food ads } / \mathrm{h} \\
\text { TV-viewing time of children at the age of } 6-12 \text { years: } 120 \mathrm{~min} / \mathrm{d}\end{array}$ & The Netherlands & $1.8 \mathrm{~min} / \mathrm{d}$ \\
\hline Great Britain & $\begin{array}{l}\text { Ofcom, department } \\
\text { Audience Analysis, } \\
\text { Strategy \& Market } \\
\text { Developments } \\
\text { (35) }\end{array}$ & 2004 & $\begin{array}{l}\text { Data are based on the UK audience measurement system } \\
\text { BARB. It measures TV viewing across more than } 250 \text { UK } \\
\text { free-to-air and commercial channels and measures TV } \\
\text { food advertising 'impacts' or 'advertising seen'. Average } \\
\text { of two TV food ads/h } \\
\text { Average TV-viewing time of children at the age } 4-15 \text { years: } \\
144 \mathrm{~min} / \mathrm{d}\end{array}$ & Great Britain & $2.4 \mathrm{~min} / \mathrm{d}$ \\
\hline United States & (22) & 2003-2004 & $\begin{array}{l}\text { National adverts assessed from } 170 \text { top-rated TV shows on } \\
\text { broadcast and cable networks viewed by children aged } \\
2-11 \text { years from } 1 \text { September } 2003 \text { to } 31 \text { May } 2004 \text {, } \\
\text { during } 9 \text { months of free-to-air TV; } 6.9 \text { food ads/h } \\
\text { Average TV-viewing time of the } 2-11 \text {-year-old children in } \\
\text { 2004: } 199 \mathrm{~min} / \mathrm{d}\end{array}$ & The United States & $11.5 \mathrm{~min} / \mathrm{d}$ \\
\hline
\end{tabular}


Table 3 Estimated fractions of childhood overweight and obesity prevalence attributable to television food advertising

\begin{tabular}{|c|c|c|c|c|c|}
\hline \multirow[b]{3}{*}{ Country } & \multirow[b]{3}{*}{ Sex } & \multicolumn{4}{|c|}{ Expected relative reductions in hypothetical situation of no TV food advertising } \\
\hline & & \multicolumn{2}{|c|}{ Bolton scenario } & \multicolumn{2}{|c|}{ Delphi panel scenario } \\
\hline & & Obesity (\%) & Overweight (\%) & Obesity (\%) & Overweight (\%) \\
\hline \multirow{2}{*}{ Australia } & Boys & $11(9,12)$ & $7(6,8)$ & $26(15,39)$ & $18(10,27)$ \\
\hline & Girls & $10(9,12)$ & $6(5,7)$ & $25(15,37)$ & $15(8,23)$ \\
\hline \multirow[t]{2}{*}{ Italy } & Boys & $11(9,13)$ & $5(5,6)$ & $27(16,40)$ & $15(8,23)$ \\
\hline & Girls & $11(10,13)$ & $6(5,7)$ & $28(16,41)$ & $16(9,24)$ \\
\hline \multirow{2}{*}{ Sweden } & Boys & $7(6,8)$ & $5(4,6)$ & $18(10,26)$ & $13(7,19)$ \\
\hline & Girls & $5(4,6)$ & $4(3,4)$ & $13(7,19)$ & $10(5,15)$ \\
\hline \multirow{2}{*}{ The Netherlands } & Boys & $6(5,7)$ & $4(3,4)$ & $15(8,21)$ & $9(5,14)$ \\
\hline & Girls & $5(5,6)$ & $3(3,4)$ & $13(8,20)$ & $8(5,12)$ \\
\hline \multirow[t]{2}{*}{ Great Britain England } & Boys & $6(5,7)$ & $4(3,4)$ & $14(8,21)$ & $9(5,14)$ \\
\hline & Girls & $4(4,5)$ & $3(2,3)$ & $11(6,17)$ & $7(4,10)$ \\
\hline \multirow[t]{2}{*}{ Great Britain Scotland } & Boys & $5(4,6)$ & $2(2,3)$ & $12(7,18)$ & $6(4,10)$ \\
\hline & Girls & $5(5,6)$ & $3(3,4)$ & $14(8,20)$ & $8(5,12)$ \\
\hline \multirow[t]{2}{*}{ The United States } & Boys & $16(14,18)$ & $9(8,11)$ & $40(23,58)$ & $26(14,43)$ \\
\hline & Girls & $16(14,19)$ & $10(8,11)$ & $40(23,57)$ & $26(14,41)$ \\
\hline
\end{tabular}

The values represent expected relative reductions, with $95 \%$ uncertainty intervals in brackets, in 6-11-year-old children.

noticeable effect of TV food advertising exposure on the prevalence of overweight and obesity in all six countries. The country with the highest overweight and obesity prevalence rates among children 6-11 years (the United States) also had the highest exposure to TV food advertising (Tables 1 and 2). Italy had an intermediate TV food advertising exposure rate, but the highest overweight prevalence rate for boys. Australia also had an intermediate TV food advertising exposure rate but the highest prevalence rate for overweight in girls. The two countries with the lowest TV food advertising rates, The Netherlands and Sweden, also had the lowest prevalence rates childhood overweight and obesity. Great Britain was an exception in having a low exposure to TV food advertising but high prevalence rates of overweight and obesity, particularly for boys in Scotland and for girls in England.

\section{Comparison with other studies}

Our study results confirm the findings of an ecological study by Lobstein and Dibb ${ }^{(11)}$ who found a significant association between the proportion of children with overweight and the number of advertisements per hour on children's TV in different countries. It is also consistent with a recent econometric study that estimated that a ban on TV fast food advertising in the United States would reduce the prevalence of overweight among children 3-11 years old by $18 \%{ }^{(10)}$. However, the findings for Australia, Italy, Scotland and England are not fully in line with the findings for The Netherlands, Sweden and the United States. An explanation might be that the studies used were not representative of the TV food advertising exposure in those countries or TV food advertising occurred through other types of marketing on TV, such as product placement, a commercial product or brand used as an integral part of a TV programme and famous personalities or cartoon characters.

\section{Policy implications}

Our study results suggest that limiting TV food advertising exposure may lead to significant reductions in the prevalence of childhood overweight and obesity.

As a result of public action and lobbying of health bodies, the majority of European countries, the United States and Australia have been trying to persuade the food industry to voluntarily restrict promotion activities of unhealthy foods through responsible self-regulation ${ }^{(19,36)}$. Such measures were introduced by the food industry in Australia in January $2009^{(37)}$, in the United States in July $2007^{(38)}$ and in the United Kingdom by media regulator Ofcom in April 2007 and January 2008 ${ }^{(3)}$. In Sweden, all broadcast advertising aimed at children under the age of 12 years has been banned since 1991 as a measure to protect the rights of children. However, the effectiveness of this ban is undermined by commercials on cable and satellite TV broadcast from other countries, for example, from the United Kingdom. European legislation prevents Sweden from stopping this advertising ${ }^{(19,26)}$. Do initiatives to reduce food advertising make an impact? According to the UK Department of Health report $2008^{(39)}$, the annual spend for child-themed TV food advertisements decreased by $41 \%$, but spending for food advertising across all media increased by $19 \%$ between 2003 and $2007^{(39)}$. As has been shown for tobacco advertising, bans may have to cover multiple advertising channels to achieve optimal effects ${ }^{(40)}$. The effectiveness of efforts to stimulate industry self-regulation is also uncertain. Caraher et $a l{ }^{(36)}$ found large differences in the enforcement and monitoring of self-regulation in twenty countries and a lack of representation of public health and consumer groups on industry self-regulating bodies. Control and regulation can be implemented regionally, as some states in Australia are considering, but preferably need to be addressed at the national or international level. In 2008, the IOTF presented the 'Sydney Principles' 
that call for international statutory actions to reduce marketing to children and the development of an International Code of Marketing Food and Beverages to Children $^{(41)}$. According to these principles, such statutory regulations should have sufficient authority, be enforced and evaluated for their impact on children's dietary patterns ${ }^{(41)}$.

\section{Recommendations for future research}

Estimates of the impact of TV food advertising on childhood obesity cannot be better than the data they are based on. There is an urgent need for more nationally representative data on the prevalence of overweight and obesity in children, in the countries studied and beyond. Similarly, there is a need for nationally representative studies on food advertising exposure on TV that use comparable methods.

\section{Strengths and limitations}

This study provides the first estimate of the effect of TV food advertising on the prevalence of childhood overweight and obesity in six Western countries on the basis of the best available evidence. The study also provides a comparison of TV-viewing data and advertising exposure in these countries.

However, the present results should be regarded as approximations of the effect of TV food advertising on the prevalence of overweight and obesity. First, the results are mostly based on BMI data from published smaller and/or localised surveys, as apart from the United States and the British studies, there were no recent national surveys available. The limited representativeness of the BMI data may have introduced bias in an unknown direction. We could only include published data, but the risk of publication bias is limited by the fact that we were looking for the largest, most representative studies, which are most likely to be published. The comparability between countries is slightly diminished by the differing dates of data collection, though, except for the Italian sample, all data were collected between 2001 and 2004. Assuming increasing trends in obesity, the more recent data probably have the highest prevalence overweight/ obesity. If the prevalence of obesity is underestimated in these data, our study overestimates the proportion of childhood obesity that is attributable to TV food advertising (however a higher absolute number of children would be affected).

Second, there is no agreed gold standard method for measures of TV food advertising exposure and we therefore had to make use of the best available information. For some countries direct estimates were available, for other estimates based on national TV-viewing patterns were combined with individual studies. Data collection of these studies was between February 2001 and March 2007; differences in the year of data collection may have reduced comparability.
Third, the real quantity of interest is exposure to TV food advertising for energy-dense and nutrient-poor foods and not for foods and drinks in general. However, such detailed advertising data are rarely available and if they were, they could not have been used in the absence of studies that quantify the effect of advertising for different food product groups on BMI.

A fourth uncertain factor is the exposure-response relationship between TV food advertising and total energy intake. The only estimate we found in the literature was the Bolton study ${ }^{(29)}$. In addition, an expert panel was asked to estimate the same relationship in a Delphi study $^{(23)}$. Both methods have their limitations. The Bolton study uses data from the United States in 1977, a context that may not be representative for the populations we applied it to. The effect of TV food advertising may be confounded with eating snacks while watching TV (regardless of advertising), since the time children were exposed to TV food advertising was not adjusted for the time spent watching TV. However, the Bolton study may have underestimated the effect of TV food advertising since it adjusts for parental influence (rules and behaviour) while adults can also be influenced by TV food commercials. In the Delphi study, a response rate of $24 \%$ and self-selection bias may have led to an overestimation of the effect of advertising.

A fifth limitation concerns the timing of the impact of TV food advertising. The data collection of the prevalence overweight and obesity studies and data collection of TV food advertising and TV viewing were approximately from the same period. Exposure takes place over an extended period of time and there may be a time delay between exposure and consequences. Our model did not include this potential delay effect. It is likely that the cumulative effects of TV food advertising to children are larger in the older age groups. However, sufficient data to support more precise analyses that include delayed and cumulative effects of TV food marketing to children over time was not available.

Lastly, our study only examines one marketing channel. The combined effect of all marketing for energy-dense, nutrient-poor foods is likely to be larger than the effect of TV food and drink advertising alone. Inclusion of other marketing channels was not possible due to data limitations.

\section{Conclusion}

The present study suggests that the exposure of children to advertising for foods and drinks on TV varies considerably by country, with a sixfold difference between the highest and lowest exposure in the countries studied. Reducing TV food advertising may significantly lower the prevalence of childhood overweight and obesity in some countries. 


\section{Acknowledgements}

The authors thank the following persons for provision of data and other relevant information. In Australia: Dr Andrea Sanigorski and Mary Malakellis, Deakin University; Kathy Chapman, the Cancer Council NSW; Bridget Kelly, NSW Centre for Overweight and Obesity; in Italy: Dr Vittorio Bini, University of Perugia; Mr Giulio Malgara, Chiarieforti Tele Media Net s.r.l; in Sweden: Louise Ekström, Swedish Consumers' Organisation; Dr Helena Sandberg, Lund University; in The Netherlands: Prof. Dr Stef van Buuren, TNO Kwaliteit van Leven; Stichting Ether Reclame; in Great Britain: Dr Tim Lobstein, Director Childhood Obesity Programme IASO - IOTF, Kam Atwal and Leila Agyeman, Ofcom and Marleen Kestens, European Heart Network. Sources of funding: The present study is partly funded from a University of Queensland Start-Up grant and a National Health and Medical Research Council Capacity Building Grant. The funders had no influence on the design and conduct of the study; collection, management, analysis and interpretation of the data; and preparation, review, or approval of the manuscript. Conflict of interest: The authors have no conflicts of interest to declare. Author responsibilities: J.M.G. is responsible for data collection, analysis, interpretation and writing of the manuscript; S.P. has provided the childhood overweight and obesity data, Umea study, Sweden, and commented extensively on the structure and content of the manuscript. E.S. has provided childhood overweight and obesity data England and Scotland, and commented on structure and content of the manuscript. J.L.V. developed the mathematical simulation model, supervised the development of the paper and provided advice regarding analysis, interpretation of data and structure and content of the manuscript.

\section{References}

1. Jackson-Leach R \& Lobstein T (2006) Estimated burden of paediatric obesity and co-morbidities in Europe. Part 1. The increase in the prevalence of child obesity in Europe is itself increasing. Int $J$ of Pediatr Obes 1, 26-32.

2. Lobstein $\mathrm{T}$, Baur $\mathrm{L} \&$ Uauy $\mathrm{R}$, for the IASO International Obesity TaskForce (2004) Obesity in children and young people: a crisis in public health. Obes Rev 5, 4-85.

3. British Heart Foundation, Children's Food Campaign (2008) Protecting children from unhealthy food marketing. A British Heart Foundation and Children's Food Campaign proposal for a statutory system to regulate non-broadcast food marketing to children. http://www. sustainweb.org/pdf/Protecting_Children_Report.pdf (accessed November 2009).

4. James WPT, Jackson-Leach R, Mhurchu CN, et al. (2004) Overweight and Obesity (High Body Mass Index). Comparative Quantification of Health Risks. Geneva: WHO.

5. Peeters A, Barendregt JJ, Willekens F et al. (2003) Obesity in adulthood and its consequences for life expectancy: a life-table analysis. Ann Intern Med 138, 24-32.

6. Wiecha JL, Peterson KE, Ludwig DS et al. (2006) When children eat what they watch: impact of television viewing on dietary intake in youth. Arch Pediatr Adolesc Med 160, 436-442.

7. Snoek HM, Van Strien T, Janssens JM et al. (2006) The effect of television viewing on adolescents' snacking: individual differences explained by external, restrained and emotional eating. J Adolesc Health 39, 448-451.

8. Utter J, Scragg R \& Schaaf D (2006) Associations between television viewing and consumption of commonly advertised foods among New Zealand children and young adolescents. Public Health Nutr 9, 606-612.

9. Robinson TN (2001) Television viewing and childhood obesity. Pediatr Clin North Am 48, 1017-1025.

10. Chou SY, Rashad I \& Grossman M (2008) Fast-food restaurant advertising and its influence on childhood obesity. J Law Econ 51, 599-618.

11. Lobstein T \& Dibb S (2005) Evidence of a possible link between obesogenic food advertising and child overweight. Obes Rev 6, 203-208.

12. Epstein LH, Roemmich JN, Robinson JL et al. (2008) A randomized trial of the effects of reducing television viewing and computer use on body mass index in young children. Arch Pediatr Adolesc Med 163, 239-245.

13. Crespo CJ, Smit E, Troiano RP et al. (2001) Television watching, energy intake, and obesity in US children: results from the Third National Health and Nutrition Examination Survey, 1988-1994. Arch Pediatr Adolesc Med 155, 360-365.

14. Halford JC, Gillespie J, Brown V et al. (2004) Effect of television advertisements for foods on food consumption in children. Appetite 42, 221-225.

15. Borzekowski DL \& Robinson TN (2001) The 30-second effect: an experiment revealing the impact of television commercials on food preferences of preschoolers. $\mathrm{J} \mathrm{Am}$ Diet Assoc 101, 42-46.

16. Institute of Medicine (2006) Food Marketing to Children and Youth: Threat or Opportunity? Washington DC: National Academic Press.

17. Chamberlain LJ, Wang Y \& Robinson TN (2006) Does children's screen time predict requests for advertised products? Cross-sectional and prospective analyses. Arch Pediatr Adolesc Med 160, 363-368.

18. Hastings G, Stead M, McDermott L et al. (2003) Review of Research on the Effects of Food Promotion to Children. Glasgow: University of Strathclyde.

19. European Heart Network (2005) The Marketing of Unhealthy Food to Children in Europe. A Report on Phase 1 of the 'Children, Obesity and Associated Avoidable Chronic Disease' Project. Brussels: European Heart Network.

20. Dietz WH Jr \& Gortmaker SL (1985) Do we fatten our children at the television set? Obesity and television viewing in children and adolescents. Pediatrics $\mathbf{7 5}$, 807-812.

21. Consumers International (1996) A Spoonful of Sugar. Television Food Advertising Aimed at Children: An International Comparative Survey. London: Consumers International.

22. Powell LM, Szczypka G \& Chaloupka FJ (2007) Exposure to food advertising on television among US children. Arch Pediatr Adolesc Med 161, 553-560.

23. Veerman J, Van Beek E, Barendregt J et al. (2009) By how much would limiting TV food advertising reduce childhood obesity? Eur J Public Health 19, 365-369.

24. Cole TJ, Bellizzi MC, Flegal KM et al. (2000) Establishing a standard definition for child overweight and obesity worldwide: international survey. BMJ 320, 1240-1243.

25. Halford JC, Boyland EJ, Hughes G et al. (2007) Beyondbrand effect of television (TV) food advertisements/ commercials on caloric intake and food choice of 5-7-year-old children. Appetite 49, 263-267.

26. Nordiska ministerrådet (2008) Prinsessmuffins och chokladägg. En analys av livsmedelsreklam till barn. Köpenhamn: Nordiska ministerrådet. 
27. Spagnoli T, Bioletti L, Bo C et al. (2003) Sovrappeso e TV: aspetti di sorveglianza nutrizionale. I tipi di spot, consumi alimentari e attività fisica. Ann $\operatorname{Ig} \mathbf{1 5}, 611-620$.

28. International Obesity Task Force (2008) Homepage. http:// www.iotf.org/childhoodobesity.asp (accessed January 2008).

29. Bolton R (1983) Modeling the impact of television food advertising on children's diets. Curr Issues Res Advertising 6, 173-199.

30. Swinburn BA, Jolley D, Kremer PJ et al. (2006) Estimating the effects of energy imbalance on changes in body weight in children. Am J Clin Nutr 83, 859-863.

31. Flegal KM \& Troiano RP (2000) Changes in the distribution of body mass index of adults and children in the US population. Int J Obes Relat Metab Disord 24, 807-818.

32. Efron $\mathrm{B} \&$ T Tibshirani $\mathrm{R}$ (1994) An Introduction to the Bootstrap. Boca Raton, FL: Chapman \& Hall/CRC.

33. Vignolo M, Pistorio A, Torrisi C et al. (2004) Overweight and obesity in a group of Italian children and adolescents: prevalence estimates using different reference standards. Ital J Pediatr 30, 53-57.

34. O'Dea J (2008) Gender, ethnicity, culture and social class influences on childhood obesity among Australian schoolchildren: implications for treatment, prevention and community education. Health Soc Care Community 16, 282-290.

35. Ofcom (2006) Television advertising of food and drink products to children. http://www.ofcom.org.uk/consult/ condocs/foodads/foodadsprint/annex10.pdf (accessed May 2008).

36. Caraher M, Landon J \& Dalmeny K (2006) Television advertising and children: lessons from policy development. Public Health Nutr 9, 596-605.

37. Australian Food and Grocery Council (2009) The Responsible Children's Marketing Initiative of the Australian Food and Beverage Industry. Barton, ACT: Australian Food and Grocery Council.

38. Council of Better Business Bureaus (2008) Changing the Landscape of Food \& Beverage Advertising: The Children's Food \& Beverage Advertising Initiative in Action. Arlington, VA: Council of Better Business Bureaus, Inc.

39. Department of Health (2008) Changes in Food and Drink Advertising and Promotion to Children. A Report Outlining the Nature and Balance of Food and Drink Advertising and Promotion to Children, from January 2003 to December 2007-2008. London: Department of Health.

40. Saffer HFC (2000) The effect of tobacco advertising bans on tobacco consumption. J Health Econ 19, 1117-1137.
41. Swinburn B, Sacks G, Lobstein T et al. (2008) The 'Sydney Principles' for reducing the commercial promotion of foods and beverages to children. Public Health Nutr 11, 881-886.

42. Sanigorski A, Bell A, Kremer P et al. (2007) High childhood obesity in an Australian population. Obesity 15, 1908-1912.

43. Celi F, Bini V, De Giorgi G et al. (2003) Epidemiology of overweight and obesity among school children and adolescents in three provinces of central Italy, 1993-2001: study of potential influencing variables. Eur J Clin Nutr 57, 1045-1051.

44. Petersen S, Brulin C \& Bergström E (2003) Increasing prevalence of overweight in young schoolchildren in Umeå, Sweden, from 1986 to 2001. Acta Pcediatr 92, 848-853.

45. Van den Hurk K, Van Dommelen P, De Wilde J et al. (2006) Prevalentie van overgewicht en obesitas bij jeugdigen 4-15 jaar in de periode 2002-2004. Leiden: TNO Kwaliteit van Leven.

46. The Department of Health Joint Health Surveys Unit, National Centre for Social Research, Department of Epidemiology and Public Health (2002) Health Survey for England 2002, The Health of Children and Young People. London: University College.

47. The Department of Health Joint Health Surveys Unit, National Centre for Social Research, Department of Epidemiology and Public Health (2003) Health Survey for Scotland 2003, The Health of Children and Young People. London: University College.

48. Centers for Disease Control and Prevention, National Center for Health Statistics (2007) National Health and Nutrition Examination Survey Data. http://www.cdc.gov/ nchs/about/major/nhanes/datalink.htm (accessed December 2007).

49. Chapman K, Nicholas P \& Supramaniam R (2006) How much food advertising is there on Australian television? Health Promot Int 21, 172-180.

50. Australian Communications and Media Authority (2007) Children's Viewing Patterns on Commercial, Free-to-air and Subscription Television. Report Analysing Audience and Ratings Data for 2001, 2005 and 2006. Melbourne: Australian Communications and Media Authority.

51. Nordicom (2006) Sveriges Mediebarometer 2005. Göteborg: Nordicom.

52. Stichting Kijk Onderzoek Nederland (2005) Jaarrapport 2005. Amstelveen: Stichting Kijk Onderzoek Nederland. 